\title{
Effect Of Stress On Employee Performance And Job Satisfaction
}

\author{
Sapna ${ }^{a}$, Dr. Asif Perwe ${ }^{b}$ \\ ${ }^{a}$ Management Research Scholar, Sangam University, Bhilwara, Rajasthan (India) \\ ${ }^{\mathrm{b}}$ Assistant Professor, Management, Sangam University, Bhilwara, Rajasthan (India) \\ sapnavpa@gmail.com ${ }^{\mathrm{a}}$ dr.asifperwej@gmail.com ${ }^{\mathrm{b}}$
}

Article History: Received: 10 November 2020; Revised 12 January 2021 Accepted: 27 January 2021; Published online: 5 April 2021

\begin{abstract}
Stress depends upon the individual and the legitimate organization dealing with the issue and centering towards progressive practicality and authoritative viability .Role stress impacts the hierarchical adequacy .Role crumbling, position over-trouble, Role stagnation and Inter occupation division are the most notable occupation stressors in an affiliation. Stress can be Eustress or hopelessness. Eustress can awaken a specialist to work with greatest limit or can inconvenience a delegate or demotivate him and thusly sway on the authoritative Effectiveness. Occupation productivity improves the various leveled suitability. There is a necessity for the associations to proceed in this resistance .However, review that individuals have restricted mental and actual resources, and can't by and large deal with the troubles they face. Laborers, now and again, need backing and getting ready which has stood up to a huge incident on account of decline. Managing the pressing factor is relied upon to adjust to the surpassing level of troubles. Stress the heads is the possibility that can be acclimated to lessen the level of pressure. It bases on shielding the sensations of tension from surpassing the level where it animates and improves the efficiency of individuals.
\end{abstract}

Keywords: Measurement, Organizational Effectiveness, Role stress, Role stressors, Role Efficiency

\section{Introduction}

The idea of stress in life science was characterized by Hans Sellie without precedent for 1936. He deciphered pressure as the power pressing factor, or strain discharged upon a material article or individual which oppose these powers and endeavour to keep up and control its unique state. Associations satisfy a more prominent assortment of our socio-practical and individual necessities. The investigation of associations is essential for directors. Stress is wherever in our general public. It has become a fundamental piece of everyday life. While clarifying the pressure, the scientists have found in the examination that it is extremely hard to enter the mind boggling zone of pressure, particularly in the region of word related pressure. Stress is an essential after effect of present day life. With the development of ventures, there is quantitative pressing factor in metropolitan zones. Development in populace and different issues in everyday life are a portion of the explanation behind expansion in pressure. Stress is a state of strain that has an immediate bearing on feelings, however measure and states of being of an individual. Steers (1981) demonstrates that expert pressure has become a significant point for the investigation of authoritative conduct for some reasons. Stress has a hurtful mental and actual impact on the staff. Stress turns into the main source of representative turnover and nonappearance. Also the pressure experienced by a representative can influence the wellbeing of different workers. By controlling sickness related pressure, individual and association can be overseen all the more viably. In start of the 20th century, the idea shows up in clinical language and as such demonstrates the over-burdening of the human body. The doctor gun (1975) related the pressure idea to harmony propensities in the body. The endocrinologist selye (1956) received this hypothesis. This pioneer in the field of pressure research has assumed a critical part in the proliferation of the idea. The pressure idea was conceded a spot in mental language after World War II. Physiological reaction to outer or inner climate issue coming about because of insight and evaluations of one's interior as well as outside occasion (French, Rogers and cob, 1974). Voluminous exploration led in the territory has set up a solid connection between job pressure and their effect on all out authoritative result. Khanna (1985) in his examination researched the connection between authoritative job pressure and its effect upon hierarchical viability. He anticipated that not just modern innovation materials and individual conduct and the hierarchical atmosphere additionally assume essential part in the assurance of the authoritative viability.

\section{Objectives}

This study is centered around the point 'Effect of organizational Role Stress on Organizational adequacy in Large Scale Industries' to comprehension on how the job pressure works in enormous scope industry across the management levels through the accompanying. 
1.Identification of noticeable job stressors for various levels.

2.To investigation the huge contrasts in encountering of each kind of job pressure and the all out job pressure across the levels.

3.To examination the Impact of role stress on organizational effectiveness.

4.To recommend measures for Improvement of Organizational Effectiveness

\section{Literature Review}

Beehr and Newman (1978) characterize word related pressure as "A condition emerging from the connection of individuals and their positions and portrayed by changes inside individuals that drive them to stray from their typical working." Cobb (1975) has the assessment that If the individual director can't adapt to the expanded obligations it might prompt a few physical and mental issues among them. Stream (1973) recognize that subjective changes in the work make change mental issue among representatives. The relational connections inside the division and between the offices make subjective challenges inside the association by and large. Nazneen et al (2014) directed an investigation on 350 top chiefs of public and private undertakings to check the degree of authoritative job pressure and stress resilience level. They found that top heads of private areas are indicating significant level of hierarchical job pressure and the prevailing stressors are job disintegration, job seclusion and entomb job distance while on account of public area undertakings top chiefs the degree of authoritative job pressure is moderate and predominant stressors are equivalent to the situation of private ventures. Nazneen and Bhalla ( 2013) led an examination on 220 employees

Miles and Perreault (1976) recognize that four unique sorts of job strife: a. Intra-sender job struggle, b . Entomb sender job strife, c. Individual - job strife, d. Job over burden. The utilization of job ideas and standards recommends that work related pressure is related with individual, relational, and primary factors (Katz and Kahn, 1978; Whetten, 1978). The presence of strong friend gatherings and steady associations with bosses are adversely related with R.C. (Caplan et al., 1964). Bhalla and Sayeed (2013) led an investigation on 150 chiefs of coordinated retail area and found that the representatives are enduring with elevated level of authoritative job pressure and the predominant stressors are job disintegration, entomb job distance, job assumption strife and individual insufficiency and low degree of hierarchical responsibility. Further they discovered negative critical connection between hierarchical job pressure and authoritative responsibility. Ivancevich and Matteson (1950) show that, "Absence of gathering cohesiveness may clarify different physiological and conduct results in a utilize craving such stays together," Workplace relational clashes and antagonistic relational relations are predominant wellsprings of stress (Dewe, 1993; Lang, 1984; Long et al., 1992) and are existed with negative disposition despondency, and side effects of infirmity (Israel et al., 1989; Karasek, Gardell and Lindell, 1987; Snap, 1992).

\section{Types Of Stressor}

The accompanying stressors beneath are stressors that influence a representative at the work environment.

1. Occupation job: this exists when the representative is befuddled on what task he/she ought to do or when the worker has overpowering measure of work to be through with so brief period. Stress could likewise emerge as a consequences of uncertainty. this model is most likely going to occur at such an occupation.

2. Underutilization: - it implies that the specialist has inadequate work to empower his/her inspiration.

3. Duty regarding others: - This expands pressure degree, if representatives face high obligation regarding others. Those who're in cost of others at the working environment and individuals better up the authoritative order are as often as possible defenseless to more strain in view of assumptions from their associates.

4. Helpless working conditions: - these conditions likewise are significant supporters of stress, these incorporate outrageous warmth, cold, commotion and stuffed

\section{Employee Performance}

Every organization carries out its operations or tasks through the help of humans, machines, materials, and money. The principal component of an organization is its human resources that is, 'people at work'. The human resource or workforce serves as the main, generating, and live resource as opposed to other resources which are non-living. Performances can be separated into organizational and employee performance.

\section{A. The Concept of Employee Performance}

Worker execution is otherwise called work execution or Individual execution. There is no basic meaning of worker execution, there exist a plenty of meanings of the term as there are different features to execution. (Jex 2002,88 ) believes that worker execution can commonly be characterized as all the conduct representatives take 
part in while at work. It might likewise allude to the occupation related exercises of a specialist and how well those exercises were executed. As indicated by (Hoppock 1957; Kane and Lawler,1976), work execution is the record identified with the outcomes subsequent to rehearsing an occupation for a given period. On the other hand, (Schermerhorn, 1989) declares that work execution alludes to the quality and amount that are achieved by singular workers or gathering of representatives subsequent to finishing a given assignment. (Motowildo and Borman 1993) characterize work execution as the amassed monetary or non-monetary added an incentive by the representatives in commitment to the satisfaction both straightforwardly and in a roundabout way to the focused on objectives of the association. Mangkunegara (2009) characterizes it as the work results dependent on quality and amount accomplished by representative in doing their work. (Rivai and Jauvani 2009) characterize work execution as the genuine conduct express by everybody as work accomplishment delivered by representative suitable to their part in the association. In view of the feelings above, it very well may be presumed that work execution is a work consequence of work accomplishment of one's quality and amount accomplished in an association in playing out its work. Workers perform various positions in an association relying on the idea of the association. Singular execution is of high pertinence to the association and people the same. As indicated by Kanfer $(2005$, 336) demonstrating superior when achieving errands brings about fulfilment, feeling of selfviability and authority. Besides, the individuals who perform well in their undertakings are generally to get advancement, grant, respected and are more open to profession openings. A decent representative exhibition is important for the association, since the achievement of the association is reliant upon the representative's innovativeness, development, and responsibility (Ramlall, 2008). Execution models are guidelines for worker conduct at work. These models contain more than how a representative accomplishes the work. Representatives are appraised on how well they take care of their responsibilities contrasted and a bunch of norms controlled by the boss. Exactly how much work a worker must do straightforwardly influences how well it is finished. Bosses tseuqer high efficiency and great administrations from representatives which must be done in promotion of the association's objectives and targets. On the off chance that representatives have an excessive amount of work, it can influence how well they perform. On the off chance that they need more work to do, the business endures.

\section{Consequences Of Stress On Employees}

Long winded pressure is characterized as "an example of high pressure followed by time periods" though constant pressure is characterized on the grounds that the "stress brought about by ceaseless encounter of stressors without alleviation. The three classifications of physiological, mental and social outcomes are the consequence of destructive ongoing pressure. Some of the indications of physiological pressure are fundamental sign , raised heartbeat and cerebral pains though the mental side effects are apprehension, despondency and unpleasantness of these feelings can cause absence of fixation, hesitation and non-attendance. In the event that people can't discover answers for their stressors they could end up inclination hopeless, distraught, and now and then won't accept the very truth that they're caught in a fanciful life. Consequences of people conduct presented to constant pressure are more noteworthy liquor utilization, rude practices, and fretfulness. the contrary result of pressure is that it can cause numerous infections. indication stress may be one among the reasons for those sicknesses; Coronary heart condition, Hypertension and malignant growth however the degree to which one individual is experiencing a pressure related infection additionally relies significantly upon what kind of character that individual has for example on the off chance that that individual has A character or B character if A characters as people who are shown in figure 1 fussbudgets, dependable, handily aggravated and serious, while B people, thoughtful, are without bother and satisfied with their work and such a characters are exceptionally less presented to pressure . 


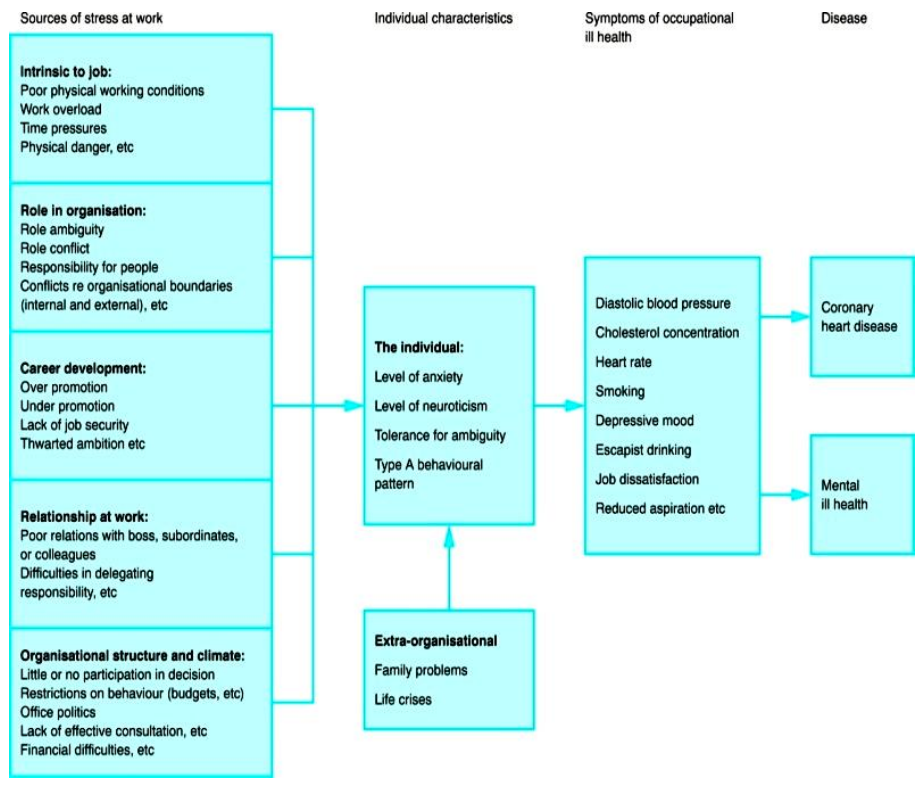

Fig. 1. Model of Stress at Work

\section{Steps Towards Stress Management For Employee And Organizations}

1 .Mindfulness: It assists with realizing when there's abatement in execution and non-appearance.

2. Deciding the source: figure out what causes this misery and its outcomes

3.Doing something profitable

Find answers for existing issuesStress may be considered as an inescapable condition at a certain point. It entangles things to deal with profitability and furthermore upset to have charming work and public activity. the essential advance towards pressure the executives is to spot signs that demonstrate pressure like uneasiness, outrage, inconvenience and so forth After these signs are perceived resulting step is to search out the causes and discover its effects. The third and last advance is to adequately influence the distressing circumstance. The distinction lies where in issue centered way of dealing with stress the stressor is straightforwardly being handled; it's either adjusted or abrogated. While in feeling centered it's just the individuals that change or discover how to adjust to the stressor during a beneficial way.

At the high degree of the board (charge) of overseeing pressure lies on the individual and hence the followings are some of the systems for managing pressure concerning work environment shown in figure 2.

1, Time the board: Schedule errands likewise, controlling one's time successfully, prioritization of assignments to be taken care of first. Here adequacy and productivity are esteemed.

2, looking for help: colleagues or chief for improving the presentation and Getting help is fitting from the board,.

3, Emotion-centered techniques: As recently examined if the stressors can't be tried not to get familiar with the best approach to adjust thereto during a helpful way has pertinence . Regular feeling centered techniques incorporate friendship, unwinding ,practice and sporting exercises. 


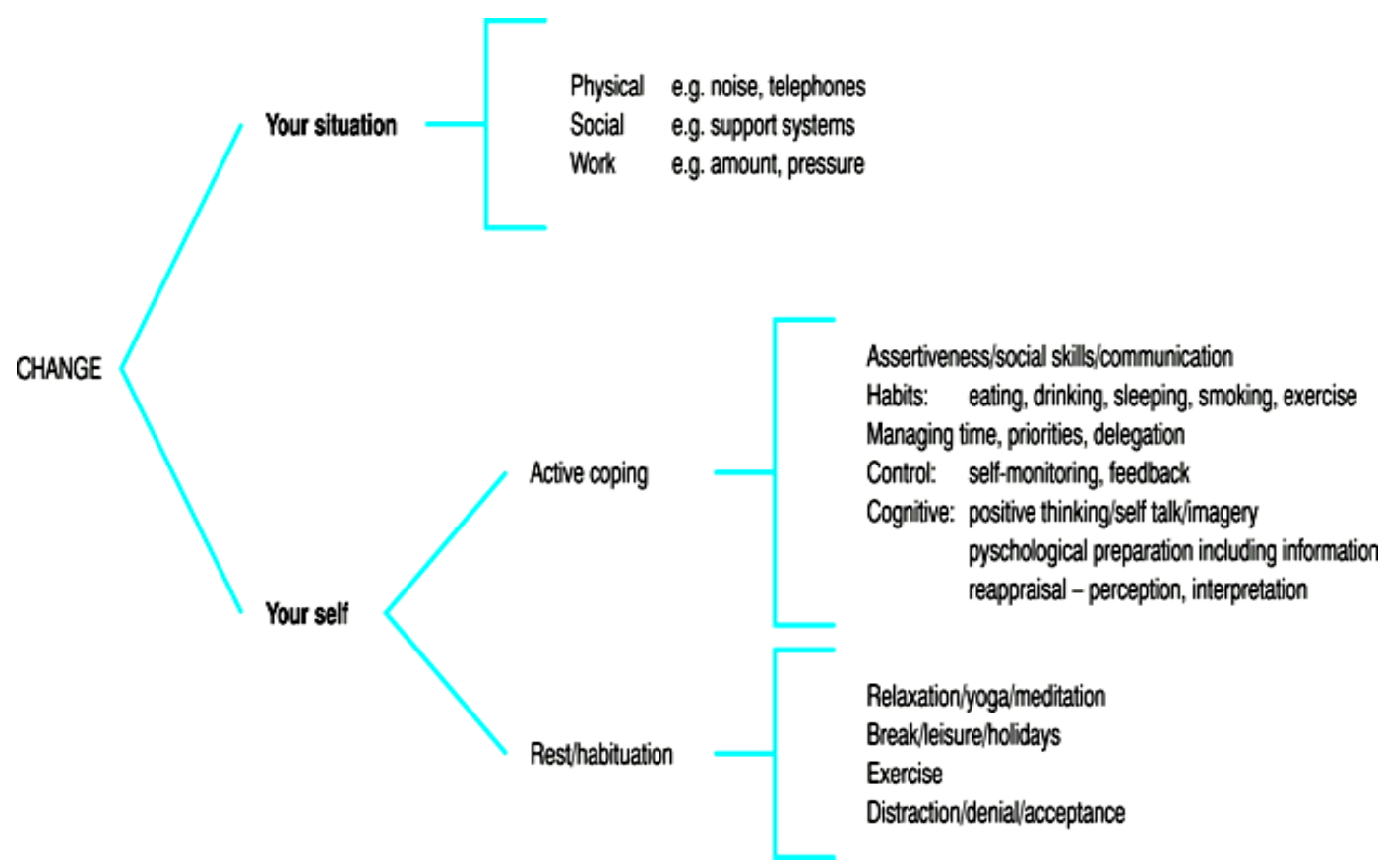

Fig. 2. Techniques for Managing Stress

\section{Organizational Approaches To StressManagement}

Chiefs can recognize pressure inside the working environment by finding work pressure difficulties, by checking regularly the worker's wellbeing and work satisfaction. Administrators additionally can forestall pressure by finding out that representatives realize where to show to once they face with such issues and following side by side of their recuperation if medical problems emerge. Human asset the executives additionally can rebuild the work accommodated the employees, by focusing on the pressure, expertise, technique and aptitudes of representatives and supply arrangement and a legit control instrument. this may be finished by changing the work environmental factors and assigning the undertaking relatively to all or any representatives. The executives ought to affirm that the employees to encourage the correct preparing to be prepared to play out their work appropriately and are up-to date and screen their turn of events.

Another hierarchical way to deal with stress the board may be having a flat line of power rather than a vertical one; this can help the employees feel great and advantageous to talk with the executives. It's likewise useful to make neighborly and aware connection among chiefs and representative. At the point when all the strain preventive measures have end up being fruitless and stress has really happened and has caused wellbeing harms to the employees then this estimation ought to be taken as additionally disclosed above to supply both individual obstructions and authoritative like clinical occupation rebuilding and guiding and so forth.

\section{Conclusion}

Working climate stress expects an enormous part in physiological and mental thriving of representatives. It moreover impacts the benefit and execution of association. The various results of workplace stress like actual issues, mental disrupting impacts, enthusiastic cumbersomeness, lifestyle aggravations and direct issues lead to agitate the environment of the association. These issues make social conflicts, decreased effectiveness, low legitimate obligation, extended delinquency and all the more consistent misfortune, etc. By empowering the workers with fruitful setting up, the administration can give them stage to deal with their pressing factor related issues. Yoga, reflection, practice and sporting activities can give better atmosphere to control pressure. For sure, even time the representatives capacities help to administer stress in a fruitful manner. These direct yet important advances can free the route for improved capability from representatives and extended benefit of association.

The end which will be reached from the speculations regarding our motivation is that the working environment reasons for pressure are work over-burden, helpless working conditions like packed working conditions and commotion. Furthermore, Employee's pressure are regularly overseen by appropriate time the executives, looking for help from HRM.. The executives assumes a significant job in assessing and dealing with the strain level of representatives at the working environment and will utilize various strategies to constrict the strain like leading instructional classes to help the representative's aptitudes, giving better workplace and guaranteeing that the laborers get appropriate direction and meeting when it's required. 


\section{References}

Nazneen. A, Bhalla, P. and Singh, N. ( 2014): “A Comparative study of ORS, Stress Tolerance Level and its Management among the top executives of Indian public and private enterprises". Paper published in International Journal of Business, Management \& Research, Vol. 4, Issue 3, 85-94.

Newman, J.E., \& Beehr, T.A. (1979). Personal and Organizational strategies for handling job stress: A review of research and opinion. Personal Psychology, 32, 1-43.

Bhalla.P \& Zafar, S (2013), "A study of ORS and Organizational Commitment in Organized Retail Sector", Research Journal of Economics and Business Studies with ISSN No 2251-1555. Sept. 2013.

Pareek, U (1976): “ Inter Role Exploration “. In J.W. Pfeiffer and J.E. Jones ( Eds.), The 1976 Annual Handbook for Group Facilitators, pp.211-224, La Jolla: University Associates. 27.

Pareek, U. (1981). Scale: Measuring role stress. Ahmedabad: Indian Institute of Management.

Pareek, U. (2004). Understanding Organizational Behaviour. New Delhi: Oxford University Press.

Vanishree, P. (2014), "Impact of Role Ambiguity, Role Conflict and Role Overload on Job Stress in Small and Medium Scale Industries", Research Journal of Management Sciences ,

Suryawanshi, S.A. and Mali, V. J., (2013), "A study on Relationship between Organizational Role Stress and Job Satisfaction", Indian Journal Of Research, Volume : 2

Cooper, CL, Liukkonen, P. \& Cartwright, S. (1996) "Stress prevention in the workplace": assessing the costs and benefits to organizations. Dublin: European Foundation for the Improvement of Living and Working Conditions.

Palmer S, Cooper C and Thomas K, (2001), "Model of organizational stress for use within an occupational health education/promotion or wellbeing programme - A short communication", Health Education Journal,

Srivastav, A.K. (2006 ). "Coping with Stress in Organizational Roles", Indian Journal of Industrial Relations, Vol 42

Beehr, T.A. (1976). Perceived situational moderators of the relationship between objective role ambiguity and role strain. Journal of Applied Psychology,13.Selye, H. (1956). A syndrome Produced by Diverse Nocuous Agents. Nature, July 4, 1936. 